\title{
Investigation of Fungi Associated with Dried Copra and Coconut Oil
}

\author{
Revati R. Nalawade ${ }^{1}$, R. R. Rathod $^{2 *}$, R. R. Kalaskar ${ }^{3}$, M. S. Joshi ${ }^{2}$, Josiya Joy ${ }^{1}$, \\ Y. K. Nirgude ${ }^{1}$, U. R. Phondekar ${ }^{1}$ and Amruta D. Gadhave ${ }^{1}$ \\ ${ }^{1}$ Department of Plant Pathology, College of Agriculture, Dapoli, India \\ ${ }^{2}$ Department of Plant Pathology, Dr. B. S. Konkan Krishi Vidyapeeth, Dapoli, India \\ ${ }^{3}$ P.R. PotePatil College of Agriculture, Amravati, India \\ *Corresponding author
}

K e y w or d s
Aspergillus
fumigates,
Chaetomium spp.,
Lasiodiplodia
theobromae,
A. niger and Copra
Article Info
Accepted:
15 September 2019
Available Online:
10 October 2019

A B S T R A C T

Fungi associated with dried copra causing deterioration of copra and copra oil were investigated under present investigation during 2017-18. For this experiment, the infected copra samples were collected from local farmers (near by Dr. Balasaheb Sawnt Konkna Krishi Vidyapeeth, Dapoli) and Regional Coconut Research Station (RCRS), Bhatye (Ratnagiri) in Konkan region of Maharashtra State, INDIA. Fungi isolated from copra samples were identified on the basis of morphological and cultural characters as Aspergillus fumigates, Chaetomium spp., Lasiodiplodia theobromae, A. oryzae and A.niger. The identifications were confirmed by Chief Mycologist, MACS- Agharkar Research Institute, (ARI) Pune.

\section{Introduction}

Coconut is unique among the plantation crops grown in India as a source of food, shelter and a variety of raw materials for industrial exploitation. Coconut industry provides sustainability to a million families and livelihood to about ten million people in India. It is known that the general standard of quality and the keeping properties of the world's copra are appallingly low in comparison with the standards of every other primary agricultural produce. A variety of factors may contribute to this. There are two groups of fungi which are known to degrade copra under tropical and sub-tropical conditions.

They can be categorized as the superficial and penetrating moulds which are confined principally to the genus Aspergillus (Nathanael, 1965). India is the largest producer and exporter of coconut and copra. The copra needs to be preserved in good quality for export purpose. It is important to identify the spoilage fungi associated with the deterioration of copra and investigate possible 
control measures. So an attempt was made to focus on following things:

Isolation of fungi associated with dried copra and coconut oil.

Proving pathogenicity of isolated fungi.

\section{Materials and Methods}

Diseased copra and oil samples were collected from local farmers in Dapoli (nearby DBSKKV area) and RCRS, Bhatye (Ratnagiri).

\section{Isolation of fungi associated with dried copra and oil extracted from copra}

The copra samples showing symptoms of infection were collected form local farmers. The copra was sliced into small pieces and these pieces were then surface sterilized in 0.1 per cent mercuric chloride for 2 minutes. These pieces were further washed thrice in sterilized distilled water to remove the traces of mercuric chloride. Such surface sterilized pieces were aseptically transferred to sterilized Petri plates already poured with sterilized potato dextrose agar (PDA) medium. Similarly, infected oil was taken with the help of pipette and single oil drop was placed at the center of Petri plates already poured with sterilized potato dextrose agar medium without spreading.

A single bit of the fungus growing on PDA was aseptically transferred on PDA slants to obtain pure culture of the associated fungus. The slants of the pure culture were preserved in the refrigerator for future use.

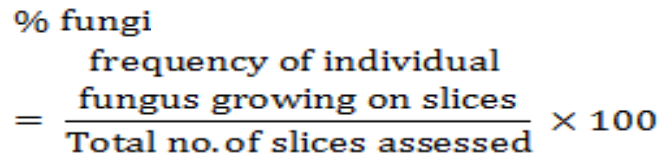

These were repeated for all samples and the experiment was repeated 3 times (Dimkpa and Onuegbu, 2010).

\section{Proving pathogenecity of isolated fungi}

Healthy copra samples were collected from Regional Coconut Research Station, Bhatey, Dist. Ratnagiri. The copra was sliced into small pieces of about 15-20 gm weight and these pieces were then surface sterilized in $1 \%$ $\mathrm{NaOCl}$ for 2 minutes. These pieces were further washed thrice in sterilized distilled water to remove traces of sodium hypochloride. The slices were respectively inoculated with the isolated fungi. This was done by dipping surface-sterilized copra slices into fungal suspension produced by homogenizing 5 discs of each fungus in $10 \mathrm{ml}$ sterile distilled water. These slices were placed in sterile Petri plates along with two bits of $5 \mathrm{~mm}$ diameter of respective culture in it. Sterile cotton plug moistened with sterile distilled water was also placed in each Petri plate containing the inoculated copra sample to provide sufficient humid conditions for growth of respective culture on copra sample. The plates were sealed with plastic tape to avoid contamination of other microorganisms.

\section{Results and Discussion}

The copra samples showing symptoms of infection were collected from local farmers and the fungi were isolated from infected portion of copra and maintained on Potato dextrose agar medium under laboratory condition for multiplication.

Colonies started developing around inoculated bits after $48 \mathrm{hrs}$ of inoculation in first sample, followed by $40 \mathrm{hrs}, 48 \mathrm{hrs}, 44 \mathrm{hrs}$ and $38 \mathrm{hrs}$ in second, third, fourth and fifth sample respectively. Five species of fungi were isolated from infected copra and coconut oil samples. These were Aspergillus fumigates, Chaetomium spp., Lasiodiplodia theobromae, A. oryzae and A.niger (Plate I and Plate II). 
Int.J.Curr.Microbiol.App.Sci (2019) 8(10): 1729-1734

\section{Plate.I}

D.C.1 Aspergillus fumigates

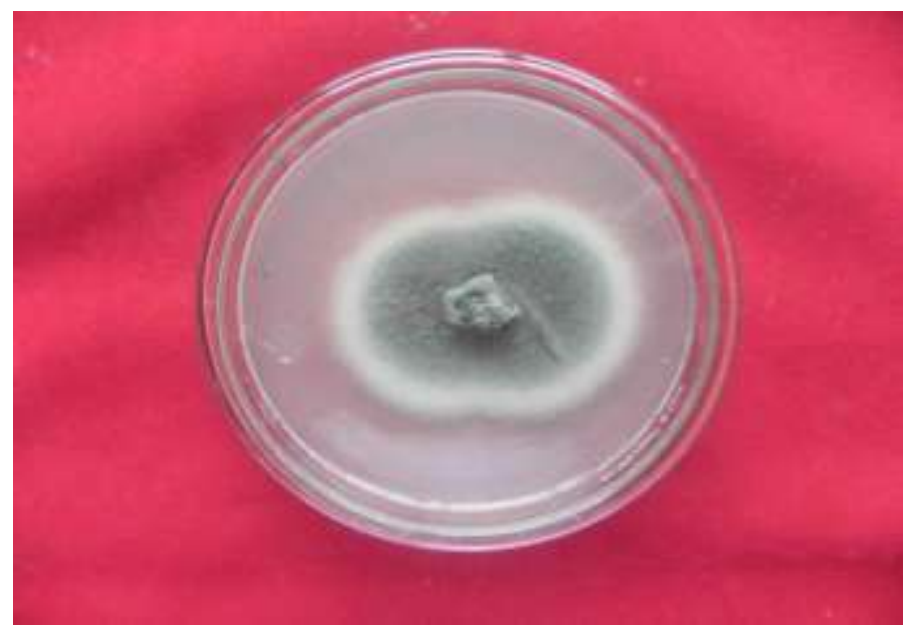

D.C.2.Chaetomium spp

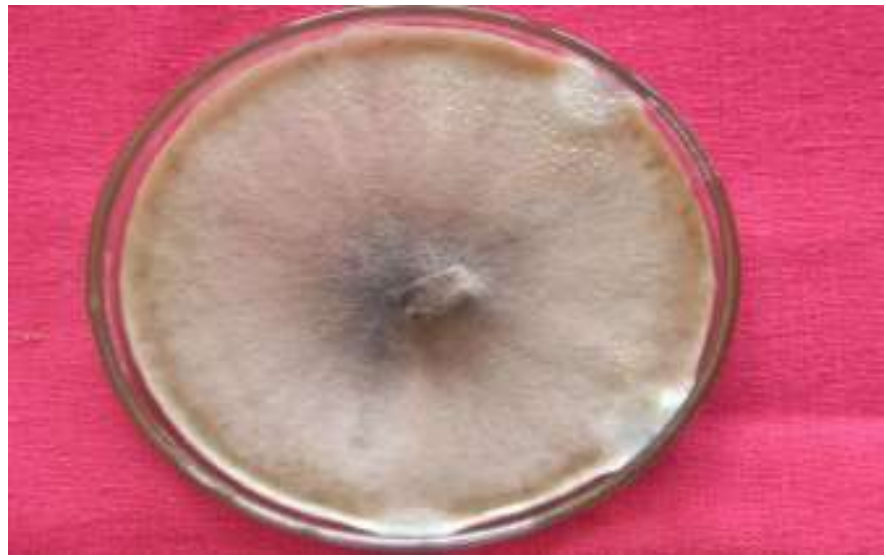

D.C.3Lasiodiplodia theobromae

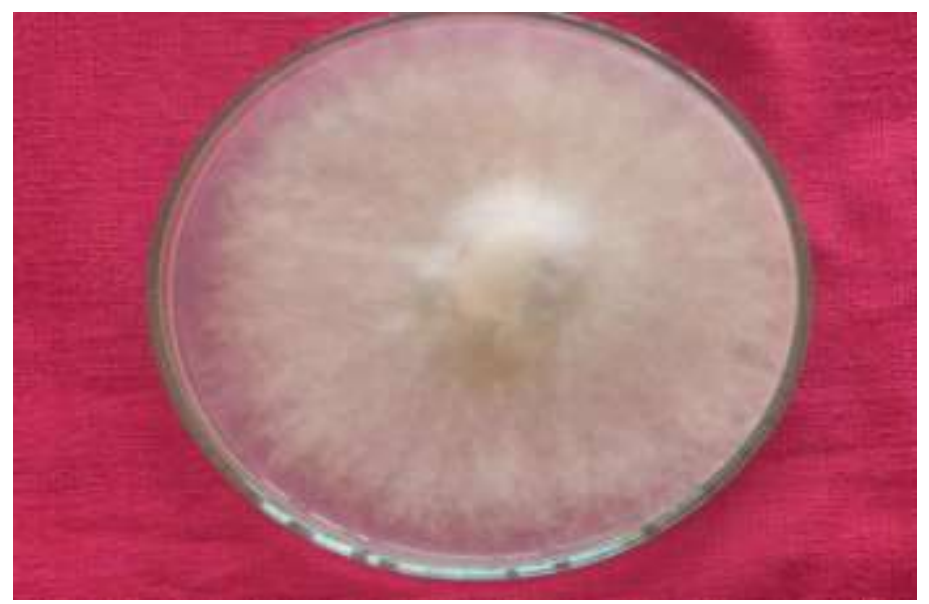




\section{Plate.II}

D.C.4 Aspergillus oryzae

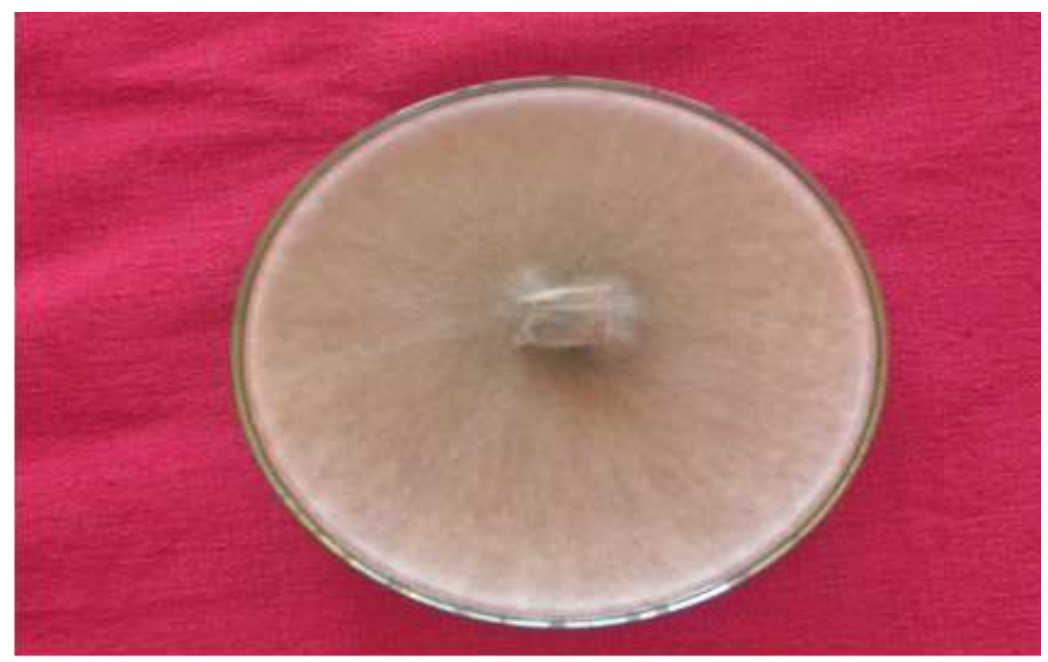

O.S.1 Aspergillus niger

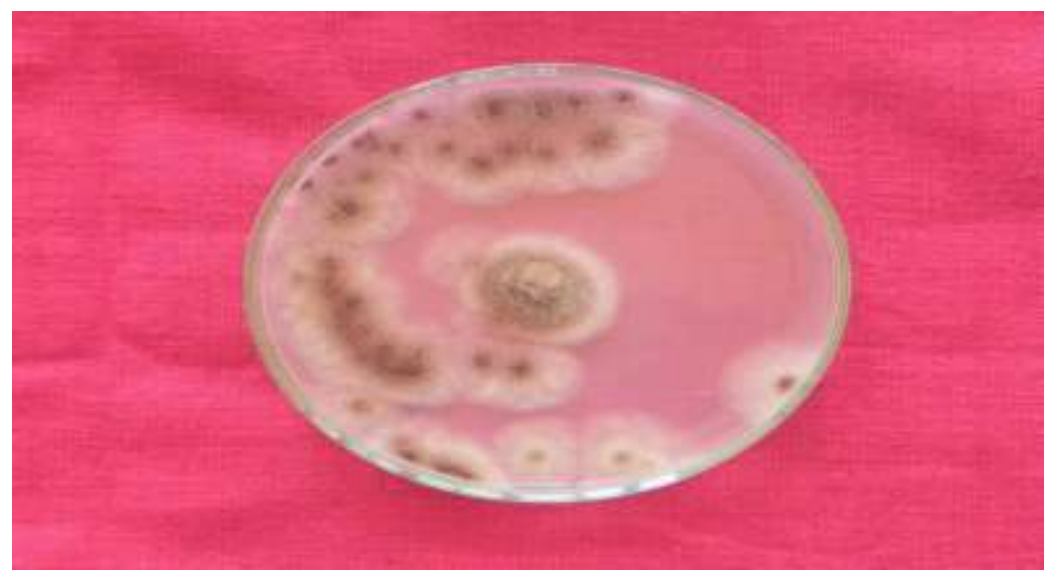

Plate.III Proving pathogenicity of isolated fungi

A. Inoculation of isolated fungi on copra sample

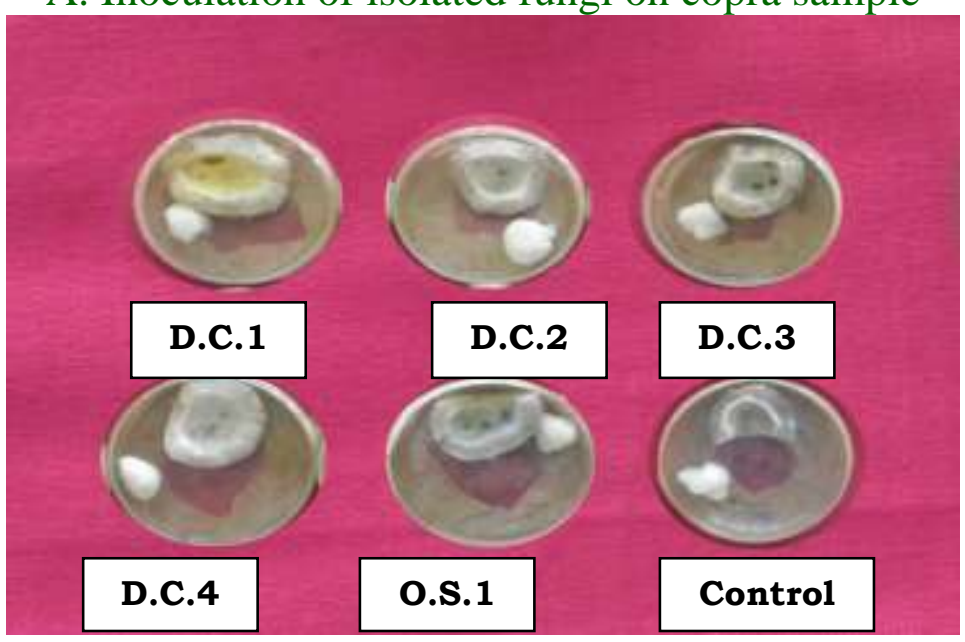




\section{B. Growth of fungi on copra sample}

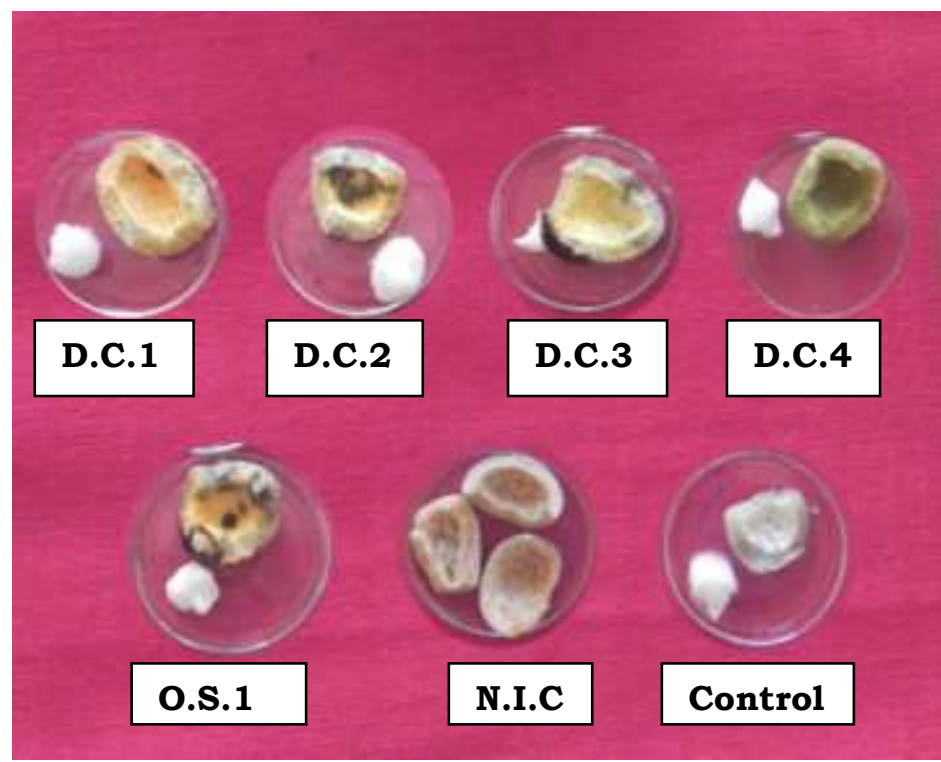

Table.1 Percentage of individual fungi isolated form diseased samples

\begin{tabular}{|l|c|}
\hline \multicolumn{1}{|c|}{ Fungi } & \% Frequency $*$ \\
\hline Aspergillus niger gr. & $83.33 \%$ \\
\hline A. fumigates gr. & $85 \%$ \\
\hline A. oryzae & $76.66 \%$ \\
\hline Chaetomium spp. & $50 \%$ \\
\hline Lasiodiplodia theobromae & $46.66 \%$ \\
\hline *= Average of three replications
\end{tabular}

The identity of cultures was confirmed by Chief Mycologist, MACS- Agharkar Research Institute, (ARI) Pune. The percentages of individual fungi are shown in Table 1.

About five species of fungi namely Aspergillus fumigates, Chaetomium spp., Lasiodiplodia theobromae, A. oryzae and A. niger were isolated form infected copra and copra oil samples in the percentage of $83.33 \%$, $85 \%, 76.66 \%, 50 \%$ and $46.66 \%$ respectively. These results are in conformity with Ward and Cook (1932), Philip (1978), Kinderlerer (1984) and Morantte et al., (1986) who isolated major fungi associated with deterioration of copra which were Aspergillus niger gr., A. fumigates gr., A. oryzae and Botryodiplodia theobromea. Venugopal S. and Chandra Mohanan R. (2006) had found Lasiodiplodia theobromae to be the major fungus causing fruit rot and immature nut fall in coconut.

Isolated fungi were inoculated on healthy copra samples for proving pathogenicity. The fungi started growing on copra sample 4-5 days after inoculation. Complete growth was observed on 7-10 days after inoculation. Sporulation of inoculated fungi was observed on 10-11 days after inoculation (Plate III).

\section{References}

Dimkpa, S.O.N. and Onuegbu, B.A., 2010. Mycoflora of copra and Effect of Brining on some properties of copra in Nigeria. Agric. 
Biol. J. N. Am., 1(3): 391-394.

Kinderlerer Judith L., 1984. Fungi in desiccated coconut. International Journal of Food Microbiology, Vol.1, 205-207.

Kinderlerer Judith L and Rachel A. Clark, 1986. Microbiological quality of desiccated coconut. J. Hyg., Camb., 19-26.

Morantte A.P.; Palomar M.K.; Lim J.L., 1986. Fungal infection and its effect on stored sun dried copra. Annals of Tropical Research, Vol. 8(1): 32-41.

Naseema A. and K.I. Wilson, 1998.Fungal deterioration of oil cakes during storage. Ind. Phytopath, Vol. 51(3), 240-243.

Philip Susamma, 1978. Investigations on the Microbial Deterioration of Copra. A thesis submitted to Kerala Agricultural University, Kerala.

Venugopal S. and R. Chandra Mohanan, 2006. Role of fungi in fruit rot and immature nut fall of coconut. Cord, Vol. 22 (2), 33-40.

Ward and Cooke, 1932. Copra deterioration. Mal. Agric. J., Vol.36: 7-11.

\section{How to cite this article:}

Revati R. Nalawade, R. R. Rathod, R. R. Kalaskar, M. S. Joshi, Josiya Joy, Y. K. Nirgude, U. R. Phondekar and Amruta D. Gadhave. 2019. Investigation of Fungi Associated with Dried Copra and Coconut Oil. Int.J.Curr.Microbiol.App.Sci. 8(10): 1729-1734. doi: https://doi.org/10.20546/ijcmas.2019.810.201 